\title{
Dare we rethink informed consent?
}

\author{
M de Roubaix, MMed, MD, DPhil \\ Centre for Applied Ethics, Department of Philosophy, Stellenbosch University, Cape Town, South Africa
}

Corresponding author: M de Roubaix (malcolmderoubaix@gmail.com)

\begin{abstract}
Current informed consent practices conform to the informed consent paradigm (ICP). Our intention is finally to promote patient autonomy through the provision of information intended to remove the information (i.e. power) differential between doctor and patient. ICP is fundamentally flawed, since it is impossible to comprehensively and explicitly inform. A fundamental problem is our reliance on the containerconduit metaphor of informing. As a linguistic act, this metaphor conceptualises the process of informing as passive, when in reality informing and consequent sense-making are parts of an individualised, personal and active process. The difficulties of the ICP are discussed, as are possible alternative strategies (reverting to paternalism, retaining the illusion of autonomy, and de-linking informing/consent, or the moral and legal aspects of consent). Alternative models are also discussed (e.g. Manson and O'Neill's notion of informed consent as a transaction). Concluding suggestions include drawing on an ethics of responsibility, incorporating the notion of informed consent as a transaction, debating the issues raised here and promoting the ethical empowerment of practising doctors.
\end{abstract}

SAfr J Bioethics Law 2017;10(1):25-28. DOI:10.7196/SAJBL.2017.v10i1.507

Modernity - that phase of societal history from the discovery of science (let's say, the discovery of the telescope) to the detonation of the Hiroshima bomb - is characterised by the overarching belief in one final and universal truth, be it about science, religion or human behaviour. In contrast, postmodernity defies this notion, and describes the current phase of human societal development as fundamentally complex, truth as something provisional and contextual, and ethics as something to be created in the quagmire of vibrant human interaction. ${ }^{[1]}$ This echoes a haunting note spanning more than two millennia - the Socratic injunction to constantly re-examine societal truth claims in the light of newer developments. With these thoughts in mind, I take a fresh and provocative look at the accepted paradigm of informed consent in clinical and research settings.

\section{The informed consent paradigm}

In the normal run of human affairs, and particularly in matters medical, whatever we do to others should be governed by their freely given and informed consent. This has both legal and ethical foundations. Legally, we may face criminal or civil litigation on grounds of assault or crimen injuria if we so much as touch a patient without her consent. ${ }^{[2]}$ Patient consent is based on what a patient knows and understands about the given medical situation/proposed treatment/envisaged research. In litigation against doctors, it is often contended that information provided was inadequate in that complications had not been disclosed; only rarely is frank negligence argued (it might also be more difficult to prove). There are numerous laws and guidelines that address both the mandatory nature and extent of informed consent in clinical and research practice, such as the SA Bill of Rights ${ }^{[3]}$ and the National Health Act No 61 of $2003,,^{[4]}$ to name but two in South Africa (SA). The ethical foundation to informed consent is that by gaining it, we show our respect for others as moral agents, and promote their personal autonomy - the ultimate aim of informed consent. ${ }^{[2]}$ The autonomy argument goes as follows: the information/knowledge asymmetry between the two parties implies a corresponding power differential, promoting paternalism and coercion, and problematising free choice. The way to correct this is to provide or supply information to the patient, which (theoretically) eliminates the power differential, thereby empowering the patient to rationally deliberate and make free and informed decisions. This is the essence of the so-called informed consent paradigm (ICP). A consequence not generally appreciated is that the doctor/researcher-patient/participant interaction assumes characteristics of a contractual agreement, and its moral content consequently diminishes (the only moral aspect of a contract or agreement once it has been agreed to is the responsibility that it be honoured). ${ }^{[5]}$

But there are many problems inherent in this notion, and the demands made upon us in order to justify an authentic consent process are onerous. In this short reflection I aim to focus on one problematic issue only: the nature of and the transfer of information. My arguments are loosely based on a provocative book by Manson and $\mathrm{O}^{\prime} \mathrm{Neill}{ }^{[6]}$ although others have voiced similar concerns.

\section{The container-conduit metaphor: The process of informing}

The metaphors we generally use when talking (and thinking) about information and the process of informing describe our general conceptions of the matter. We conceive of information as content passing from one person to another like contents flowing passively via a conduit from one vessel to another (the container-conduit metaphor). ${ }^{[6]}$ Other metaphors we commonly use (some are italicised above to show just how pervasive their usage is) support this notion, implying that we conceive of information as contents - tangible, contained or containable, packaged or like data on a memory stick/ hard drive and by implication as readily and passively transferable. Grady ${ }^{[7]}$ illuminates the container metaphor for communication: our ideas (objects) are put into words (containers) and sent (via conduits 
like our voices) to listeners who extract the ideas/objects out of the words/containers. In this explication, extracting information is an active, creative process. The essence of my argument is that the ideas packaged by medical practitioners in the informed consent communication and delivered verbally are most likely vastly dissimilar from those extracted, understood and eventually internalised by the patient - upon which she eventually decides.

The container-conduit metaphor was originally presented by Reddy in $1979,{ }^{[8]}$ and served as inspiration for Lakoff and Johnson, ${ }^{[9]}$ who laid down the principles for the current theory of conceptual metaphors. Human linguistic communication is well-nigh inconceivable without the use of metaphors, the usage of which is essential and so pervasive as to pass unnoticed unless specifically studied. Conceptual metaphors are not the passive linguistic adornments we often conceive them to be, but cognitive speech-acts; metaphors reveal not only what, but also how we think about matters, and also how knowledge discloses itself to us. ${ }^{[10,11]}$ So, in conceiving of information as ideas readily packageable into words, easily transferred to patients and as easily and clearly extracted and understood by them, we reveal our belief that the process of informing is passive and simple, as simple as pouring content from one container to another, or transferring digitally stored data, or, well, simply telling someone.

\section{Informing is an active, not passive process}

But what then is the nature of 'informing' (Manson and O'Neill use the word information as a verb), and how does the patient/ research participant make sense of the words she hears (i.e. extract information and turn it into knowledge)? The original meaning of the verb 'to inform' (to shape, like a sculptor) illustrates the multifaceted, complex and active process that informing really is, starting with sense-making. ${ }^{[1]}$ But first, ideas have to be extracted from their word packages, and the ability to do this depends on individual linguistic ability and familiarity with the subject matter. Limitations in these respects are bound to lead to difficulties in reconstructing the original ideas as understood by the informant. But let us accept that there is sufficient understanding by the patient to extract the gist of the ideas originally packaged by the medical professional (normally not an expert in the art/science of communication). The next step is to make sense of these ideas. Subjective issues now come into play. Disease has changed the circumstantial and emotional environment of the patient, resulting in experiential discontinuity. Each individual patient has previous individual experience or knowledge that provides a unique matrix in which any new information is organised and laid down. There is selective retention of newly compounded experience for immediate or future use and sense is made through enactment - a sort of data-interpretation-action (Moore, W. Unpublished PhD, 2010, Stellenbosch University). The process is unique and contextual within each patient's own frame of reference, cognitive ability and past experience, culture and understanding through language proficiency. Remaining gaps in the existing knowledge matrix are plugged with new knowledge, which is created or transformed from implicit, explicit (provided) and cultural knowledge. Therefore, knowledge so newly created and internalised is likely to differ considerably from that understood by the doctor, and the same information imparted in the same way to different patients is likely to be interpreted differently. Add to this that no two doctors would package the same ideas in the same words, or deliver them in the same way.
The eventual aim of becoming informed is rational deliberation in the face of existing choices. A prerequisite to rational deliberation is being informed: having a clear understanding of all relevant facts and opinions expressed by the doctor, in the absence of which the notion of informed consent is doomed.

The process referred to above not only takes place within the mind of a person with a particular frame of reference and acculturalisation, but is influenced by emotions and other extraneous influences (e.g. the opinions and emotions of family members). It is a journey or process rather than an instantaneous act. Thus meaning is individually, contextually and actively created.

\section{Prerequisites for the ICP}

The prerequisites for the ICP to succeed in both clinical and research informed consent are that informing must be both fully comprehensive and explicit, which Manson and $\mathrm{O}^{\prime} \mathrm{Neill}^{[6]}$ argue it can never be. If these two conditions are not met, it follows that the information requirement fails; thus the notion that we promote autonomy by empowering patients/participants through informing them and diminishing the information-based power differential also fails (at least, partially) simply because we are not really informing them, at least not comprehensively and explicitly.

Not all clinical medical acts of informing are so complex as to justify this concern. If, for example, an abscess requires drainage, the nature of the subject matter, ready reference to visible pathology and relatively simple surgery imply an uncomplicated informed consent process (consent for the anaesthetic is sought separately and might be more complex). However, imagine a common occurrence in the SA public health system: informed consent has to be obtained but neither of the parties is fluent in the other's home language and the patient may need to undergo a complex procedure such as transarterial cannulisation and cryo-ablation of an aberrant intra-cardiac conduction path that causes ventricular tachy-arrythmias or irritable focus that initiates atrial fibrillation. How does one understandably package in words the information you need to transfer, and how is this information eventually recreated by the recipient? How authentic is autonomy-based informed consent? Secondly, in medical, particularly clinical drug-related research, the process and nature of informing can be very complex (drug study informed consent documents are extremely complex and may be more than 20 typewritten pages in length; even research ethics committee (institutional review board (IRB)) members may struggle to fully understand these complexities) and the concerns raised above are fully justifiable. Again, we may question the authenticity of eventual informed consent. For this reason Moore (Moore, W. Unpublished $\mathrm{PhD}, 2010$, Stellenbosch University) has argued that there is space for a dedicated information therapist/ethics consultant to facilitate the process of informed consent. On top of this, informed consent in the clinical situation should be contextually (i.e. subjectively) tuned to the patient's frame of reference and level of understanding, in a way justifying diminished informing. ${ }^{[4]}$

\section{Alternatives to the ICP}

However, informing patients and obtaining their uncoerced prior, socalled informed consent, flawed as it might be, remains an undeniable moral and institutionalised legal requirement. So if the ICP fails, what alternatives do we have? There are several possibilities: 


\section{Revert to paternalism}

Respectfulness of human life and respect for humans are fundamental philosophical and legal tenets and non-negotiable practice guidelines (think for example of the Kantian dictum to treat others always so that their own interests are also served ${ }^{[12]}$, or the South African Bill of Rights $^{[3]}$ and the National Health Act ${ }^{[4]}$ ). If paternalism implies exerting control over others, it is therefore not an option. One could argue for a benign form of paternalism (in the original meaning of the word, as a father would care for his children), but this may be as problematic as arguing for the notion of benign dictatorship. Besides, 'prejudging that the sick are not fully autonomous is biased' and unsubstantiated, and for most practitioners, technical expertise 'does not include the ethical qualifications and prerogative to decide for others'.[13]

\section{Retain the illusion of autonomy}

I argue that we effectively and unwittingly often practise some limited degree of autonomy combined with some degree of paternalism (flawed but 'good-enough' or 'minimalist' informed consent). This is unsatisfactory and poses several questions, for example, how reflective should choices be? How do we define acceptable informed consent? Why should limited autonomy be honoured and override other important principles? ${ }^{[6]}$ Manson and $\mathrm{O}^{\prime} \mathrm{Neill}^{[6]}$ call this minimal autonomy intended to secure a form of rational autonomy. But to call choices made on this basis reflective may justify too much (when patients elect dangerous choices) or too little (when dealing with complex interventions). Furthermore, if autonomy is equal to mere choice, equal protection for irrational choices is mandatory. Vice (Vice S. Unpublished paper and personal communication: March 2004. Used with consent) has argued that autonomy for its own sake is void of any ethical purpose (for her, respecting autonomy and autonomous choice should serve a purpose - instantiating the 'good life' according to individual dictates). If comprehensive and explicit informing is impossible, it implies that we accept that many patients de facto have limited competence, and should either be denied treatment or treated with paternalism.

\section{De-link the information and consent components of informed consent}

This defensive mode of practising entails informing as well as possible, realising its limitations and obtaining consent for legal purposes, with limited emphasis on truly autonomous choice. Similarly, we may also de-link the moral and legal aspects of informed consent while emphasising moral obligations and sincerely attempting to treat others as a moral agents even if this is not fully autonomous informed consent. The legal requirement for informed consent is again met as a defensive practice strategy (to prevent litigation or complaints to the Health Professions Council of South Africa).

\section{Evaluate alternative models of informed morally acceptable doctor patient relationships}

I discuss only two:

\section{An ethics of responsibility}

This notion expresses, perhaps a bit more coherently, the essence of the third options above, and may be developed from the work of Jonas ${ }^{[14]}$ and Bauman. ${ }^{[5]}$ Jonas emphasises the responsibility humans have for others, responsibility that spans time and space, and Bauman describes the moral nature of this responsibility. Recognition of need in others and an ability to respond appropriately to that need and consequent action legitimate one as a moral agent, and are the foundations of morality. This responsibility is awesome in scope and content. It is not limited, and not based on nor demands reciprocity. Without assuming that such an onerous notion is appropriate to medical practice, any serious attempt at this form of practice would ensure prime care and prime attention to ethical responsibility, and would be incompatible with practices that do not take patient interests and consent seriously, but would not necessarily be as onerous as the ICP.

\section{Informed consent as a transaction}

Informed consent as a transaction can be defined as'a communicative action or activity involving two parties or things that reciprocally affect or influence each other ${ }^{\prime[6]}$ This notion is unique in recognising that informing can never be comprehensively explicit and specific. Consequent consent would therefore not satisfy the arduous demands of the paradigm model, or fundamentally promote autonomy. Instead of promoting paternalism, we de facto rely on a (limited and contextual) waiver of the legal and ethical claims attendant to treatment without so-called fully informed consent. ${ }^{[6]}$ The scope of the waiver is determined by the scope and nature of the legal/ethical norms that need to be waived in order to treat (i.e. the scope and nature of treatment). The notion emphasises the type of communicative action that the process of informing should be: reciprocal flow between two moral agents. It legitimises relative instead of absolute explicit/specific informing. But there are certain protective norms inherent to effective communication, for example comprehensibility, relevance and accuracy, and these are the foundations of this type of interaction. ${ }^{[6]}$ In the final instance certain undertakings are made - contextually about treatment/research. This notion also responds to several characteristics of communication obscured by the container-conduit metaphor. Communication is context- and norm-dependant, propositional, a rational action (and therefore rationally evaluable), allows agents to be aware of the bigger picture and assists them in making a wide range of inferences, depending on personal circumstances and frames of reference. But fundamental to this notion is accepting that the dictates of the ICP are simply impracticable.

\section{Quo vadis? Four practical suggestions}

So what does this mean in our daily practice? I'll restrict myself to four concluding suggestions:

Bauman's ${ }^{[5]}$ notion of responsibility is probably too onerous for general medical practice (although, perhaps, it is not for the research environment, owing to its peculiar dynamics). There have nevertheless been suggestions that an ethics of responsibility might be the only coherent approach to bioethics, given the unusual inherent moral demands. This ethic 'ruthlessly demands justification and responsibility for our moral actions even if not moulded in conventional moral

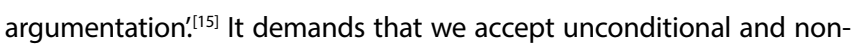
reciprocal responsibility, and be empowered with the tools of moral debate. ${ }^{[16]}$ This ethic is no lame excuse for paternalism, which develops from a totally different mind-set. As Jonas puts it: the ultimate 'purpose' is the 'ever-transcendent possibility' of human dignity. ${ }^{[14]}$ There can be no better aim in medicine. 
Seeing the informed consent process as a communicative action emphasises our moral responsibilities and the continued importance of values such as the trust placed in medical caregivers: that even if I can't know/understand everything, even if I am anaesthetised or on a ventilator, I can rely on the integrity of my doctor, and may be assured that my best interests will always predominate. This should apply to the research situation as well; in fact, more so, since research may hold risks absent from clinical settings, is not essential to the wellbeing of the patient and may hold little if any advantage for individual participants.

A solid debate of the theory $v$. the practicalities of informed consent along the lines argued before seems appropriate, although we will only make progress if we admit the incoherence of the current paradigm, and convince others - lawyers, lawmakers, theoretical ethicists - of our argument. Manson and $\mathrm{O}^{\prime} \mathrm{Neill}^{[6]}$ argue that what we do in practice probably corresponds more with their views than with current laws and guidelines. Furthermore, those responsible for formulating laws and guidelines concerning the practice of informed consent should tone down their increasingly onerous demands.

We should take the suggestion of empowering ourselves with the tools of moral debate seriously. Medical (clinical) ethics has to do with daily patient-directed doctor-patient relational/therapeutic issues and decisions, including informed consent, and the practitioner should be confident in making these decisions. These often apply to clinical research as well. Appropriate ethics courses and continued professional development events with more ethics and less medicolegal material may further serve to empower clinicians.
1. De Roubaix JAM, Cilliers P. Complexity, postmodernism and the bioethica dilemma. Acta Academica UOFS, 2008:40(2):84-11. (not available online)

2. Carstens PA. Informed consent in South African medical law with reference to legislative developments. In: Carstens PA, The South African Medico Legal Society. http://new.samls.co.za/node/410 (accessed 11 November 2011).

3. South Africa. Bill of Rights. In: Constitution of the Republic of South Africa, 1996 http://www.info.gov.za/documents/constitution/1996/96cons2.htm\#10 (accessed 12 January 2016).

4. South Africa. National Health Act No. 61 of 2003. Chapter 2, Section 6(2).

5. Bauman Z. Postmodern Ethics. Blackwell: Oxford and Malden, 1993;17-31.

6. Manson C, O'Neill O. Rethinking informed consent. Cambridge: Cambridge University Press, 2007.

7. Grady, J. The 'conduit metaphor' revisited: A reassessment of metaphors for communication. In: Koenig, J. ed. Discourse and Cognition, Stanford: CSLI Publications, 1998:205-218.

8. Reddy MJ. The conduit metaphor - A case of frame conflict in our language of language. In: Ortony A, ed. Metaphor and Thought, Cambridge: Cambridge University Press, 1979:284-324.

9. Lakoff G, Johnson M. Metaphors we live by. Chicago: Chicago University Press, 1980.

10. Ricoeur P. 1973. Creativity in language: Word, polysemy, metaphor. Philos Today, 17(2);1973:97-111.

11. Ricoeur P. The Rule of Metaphor. (Tr. by R. Czerny) London: Routledge and Kegan Paul, 1978.

12. Kant I. Grounding for the Metaphysics of Morals. Translated Ellington JW 3rd ed.. Hackett Publishing Inc, Indianapolis, 1785.

13. Kottow M. The battering of informed consent. J Med Ethics 2004;30(6):565-569. http://dx.doi.org/10.1136/jme.2003.002949

14. Jonas H. The Imperative of Responsibility. University of Chicago Press: Chicago and London, 1984

15. De Roubaix JAM, Van Niekerk AA. Separation-survivability as moral cut-off point for abortion. S Afr J Philos 2006;25(3)206-223 (not available online).

16. Van Niekerk AA. Ethics for medicine and medicine for ethics. S Afr J Philos 2002;21(1):35-43. http://dx.doi.org/10.4314/sajpem.v21i1.31334 